\title{
ANÁLISE MULTITEMPORAL DO USO E OCUPAÇÃO DO SOLO AO ENTORNO DA ÁREA DE UNIDADE DE CONSERVAÇÃO, UTINGA - PA, ANOS 2005 - 2015
}

\author{
Jaqueline Barbosa Torres $^{(a)}$, Renata Balieiro Lopes ${ }^{(b)}$ \\ (a) Faculdade de Tecnologia em Geoprocessamento, Universidade Federal do Pará, jaquelinetorresb@gmail.com \\ (b) Faculdade de Tecnologia em Geoprocessamento, Universidade Federal do Pará, renata.balieiro@ yahoo.com.br
}

Eixo: Uso e ocupação das terras e legislação ambiental

\begin{abstract}
Resumo
O trabalho tem a finalidade de análisar o uso e ocupação do solo no periodo de 2005 a 2015 nas áreas de preservação ambiental que abrangem os municípios de Belém e Ananindeua onde localiza- se o parque ambiental Utinga. Houve a classificação survisionada pelo método de máxima verossimilhança para a quantificação da area estudo. Estabelecendo um parâmetro de comparação entre os itens quantificados como: Área urbana e solo exposto, grama, hidrografia e vegetação no periodo de 10 anos.

Palavras chave: Unidade de conservação. Ocupação. Quantificação. Classificação.
\end{abstract}

\section{Introdução}

O Parque Ambiental Utinga foi estabelecido pelo decreto Estadual $n^{\circ}$. 1552/1993. Desde sua criação percebeu-se ocupações irregulares no entorno do parque devido ao crescimento da região metropolitana de Belém impulsionando avanço da urbanização sobre as áreas de preservação permanente. Deixando assim, as áreas de proteção ambiental comprometidas em razão da grande pressão ambiental decorrentes do crescimento populacional e como consequências é notório os impactos ambientais causando modificações físicas e sociais na cidade.

Entretanto, a partir de 2005 houve uma estabilidade no avanço da malha urbana sobre essas áreas e um dos motivos foi a instalação de uma base do Batalhão da Polícia Ambiental (BPA), criada pelo Decreto n. 4.749/2001. O Parque Estadual do Utinga (PEUt) é uma Unidade de Conservação (UC) de proteção integral em que conforme a Lei 9.985 (BRASIL, 2000), destina-se à manutenção dos ecossistemas livres de alterações antrópicas, admitindo somente uso indireto dos seus recursos. Tem a importante função de proteger os mananciais: Água Preta e Bolonha, responsáveis por abastecer água para grande parte da região metropolitana de Belém (BAHIA et al., 2011; PARÁ, 2013). 


\section{OS DESAFIOS DA GEOGRAFIA FÍSICA NA FRONTEIRA DO CONHECIMENTO \\ Instituto de Geociências - Unicamp \\ Campinas - SP \\ 28 de Junho à 02 de Julho de 2017}

A cidade enquanto construção humana, produto social, trabalho materializado, apresenta-se diversas formas de ocupações. O modo de ocupação da cidade se dá a partir da necessidade de realização de determinada ação, seja de produzir, consumir, habitar ou viver. CARLOS (2001, p.45).

\section{2. Área de Estudo}

O estudo foi realizado na Área de Preservação Ambiental (APA) com área de 7.500 hectares, pertencente à Região Metropolitana de Belém. Levando em consideração o Parque Ambiental Utinga (PEUt), de latitude $1^{\circ} 25^{\prime} 14.62$ 'S e longitude $48^{\circ} 26^{\prime} 21.39^{\prime}$ 'O. PEUt é uma unidade de conservação ambiental (UC) de proteção integral do estado do Pará criado a partir com área de 1.393 ha, estabelecida pelo Decreto Estadual $n^{\circ}$. 1552/1993. O acesso viário é feito pela rodovia BR- 316 que liga o município de Belém ao nordeste e ao sul do país, e a rodovia PA-150 que interliga diversos municípios do Pará e do Nordeste brasileiro (PARÁ, 2002, 1994).

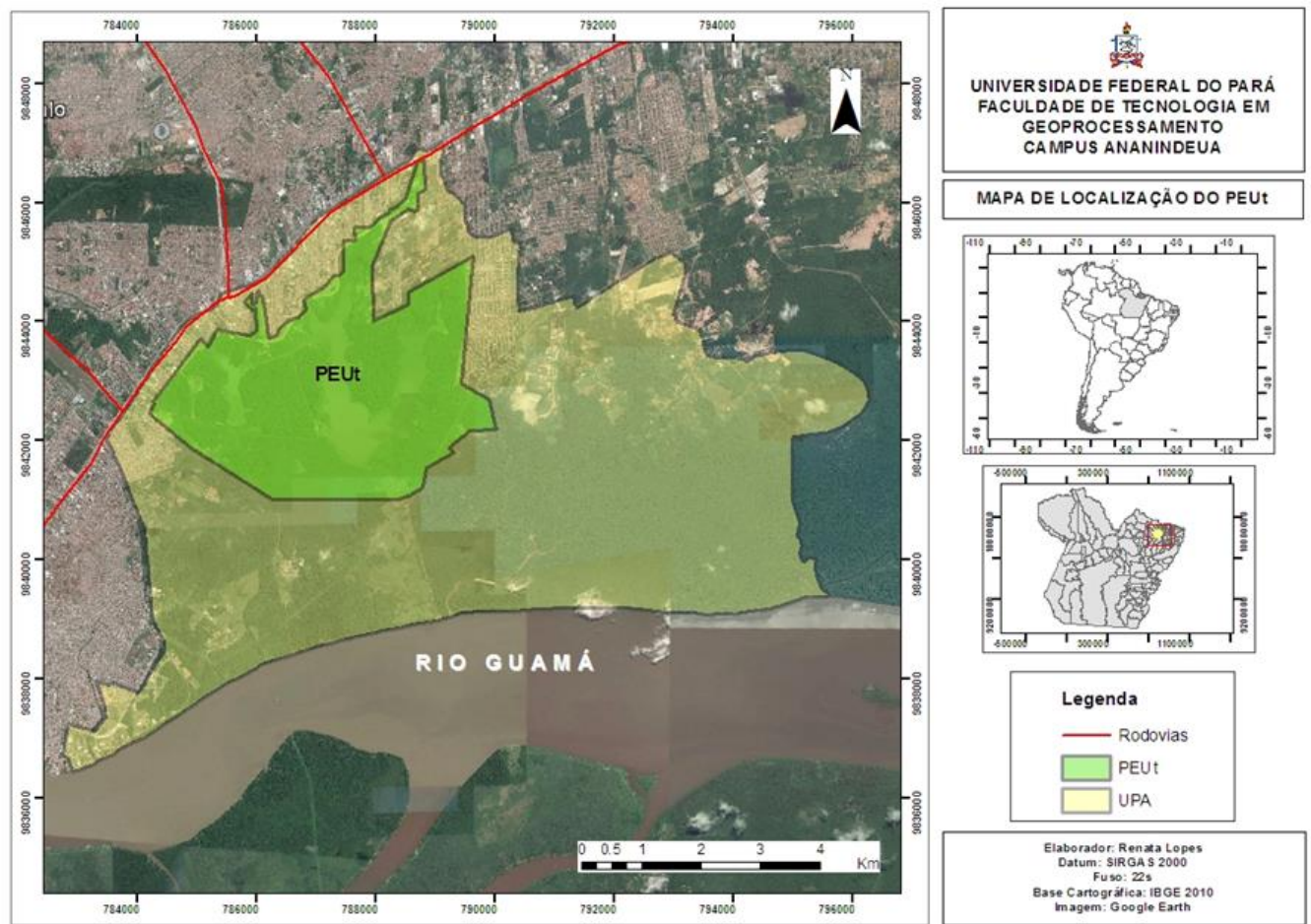

Figura 1: Mapa de localização do Parque Ambiental Utinga Fonte: LOPES, 2017.

\section{Materiais e Métodos}

Para elaboração do Mapa de uso da terra e cobertura vegetal foram utilizados dados: vetoriais de limite municipal do IBGE (2010), e imagens de Landsat-5 (22/04/2005) e Lansat-8 (15/08/2015) com orbita 
221.62, obtida no catálogo de imagens do Instituto Nacional de Pesquisas Espaciais (INPE). Os mapas foram elaborados no laboratório de Cartografia e Geoprocessamento da Faculdade de Tecnologia em Geoprocessamento da Universidade Federal do Pará, utilizando o software Arcgis 10.1 com a composição RGB de bandas 547 para Landsat-5 e 764 Landsat-8.

O processamento das imagens foi realizado através do método classificação supervisionado pelo algoritmo da Máxima Verossimilhança, método supervisionado e paramétrico de acordo com as distribuições Gaussianas, envolvendo parâmetros (vetor, média e matriz covariância). Esse método de classificação parte do pressuposto que o usuário conheça previamente a área analisada, bem como a distribuição das classes, para que desta forma, quando a aplicação da classificação e seleção de amostras de treinamento possa ser o mais eficiente possível (Crósta, 1993). Foram feitas classificação de área urbana, solo exposto, grama, hidrografia e vegetação assim, analisando a cobertura vegetal do uso do solo e quantificando a area total da APA foi possível fazer melhor analise dos processos de ocupação do uso da terra.

\section{Resultados e Discursões}

Tendo como base os resultados das análises da classificação supervisionada do mapa sobre uso e ocupação do solo foi possível perceber uma variação no uso da terra no intervalo de dez anos (2005-2010). Foram analisados área urbana e solo exposto, grama, hidrografia e vegetação. A quantificação da área urbana em 2005 obteve um resultado de $21,38 \%$ e em 2015 a porcentagem de 17,93\%. Notamos que houve uma redução de área urbana 3,45\%, mas analisando a imagem percebemos que área de solo exposto 2005 reduziu em 2015 e isso foi em razão do crescimento da cobertura vegetal de gramínea, essa que era de $24,33 \%$ em 2005 e passou para 25,83\%, tendo um aumento de 1,5 nesses dez anos.

Com isso, a vegetação que em 2005 era de 48,04\% aumentou para 51,44\% em 2015, tendo um aumento de $3,4 \%$, considerando o crescimento da vegetação de porte médio. E o resultado do último item da classificação, a hidrografia teve um decline-o de 1,5\%, pois em 2005 era de 6,23\% e em 20015 ficou 4,75\%. Observamos que essa redução foi em razão da qualidade da imagem de 2005 utilizada ocorreu um erro de leitura de pixel, tornando assim esse último resultado irrelevante. Podendo se visto no mapa a seguir. 

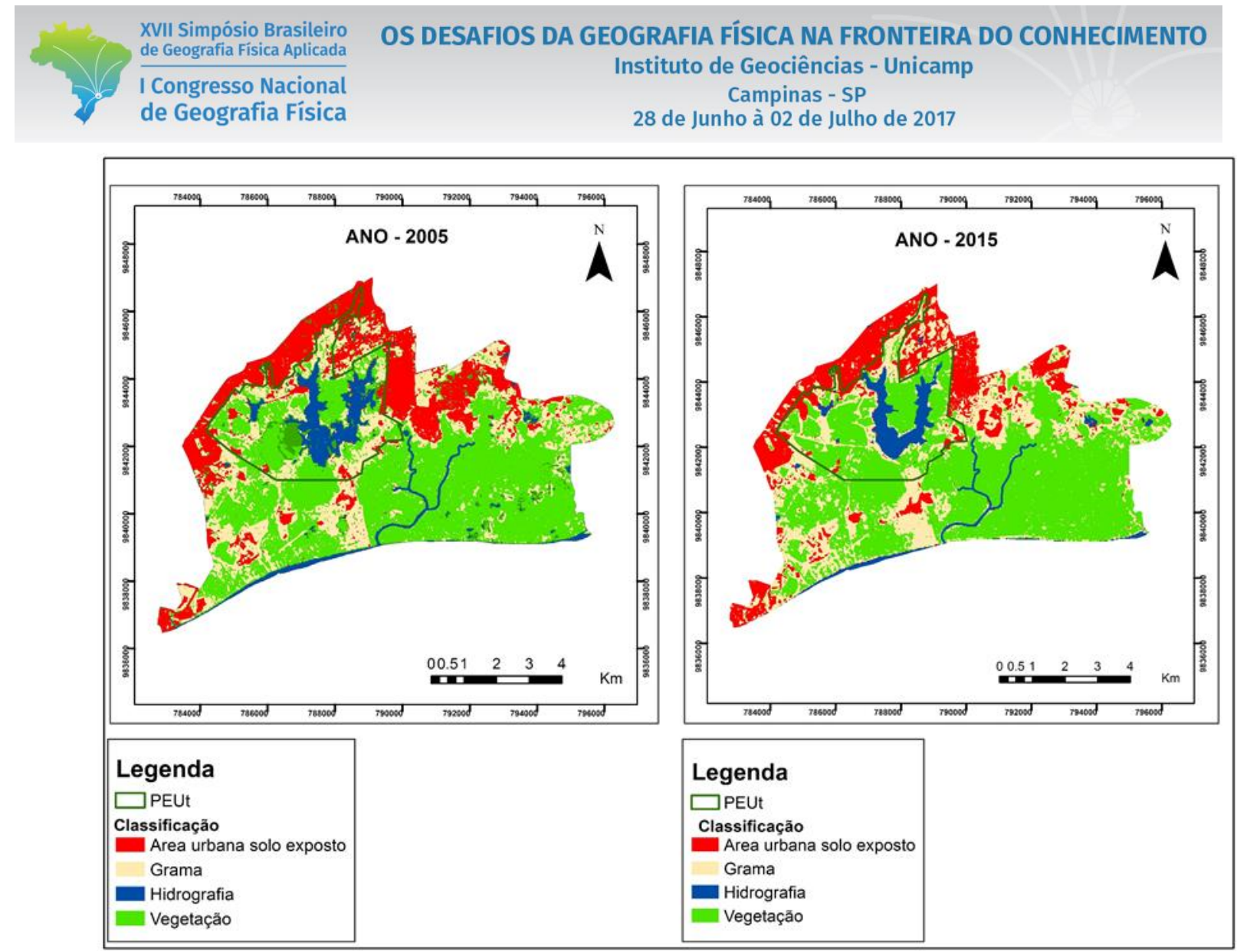

Figura 2: Mapa de uso do solo no PEUt Fonte: LOPES, 2017.

\section{Considerações Finais}

Analisando os resultados da classificação supervisionada foi notório que o processo de ocupação no solo ao entorno do Parque Ambiental Utinga entrou em processo de estabilidade e regeneração da vegetação nativa, com aumento de graminea. Houve redução das as áreas de solo expostos em razão da maior fiscalização por parte da policia ambiental que atua com uma base dentro da área do Parque Estadual ( PEUt), atuando com o monitoramento das florestas, hidrografia e tudo que for relacionado ao meio ambiente.

\section{Bibliografia}

BRASIL, A,B; PAUMYARTTEN, A.E.A; BRAGA, A.B; MARCIEL, M.N.M; SILVA, P.T.E. Dinâmica Da Cobertura E Uso Do Solo No Entorno Do Parque Estatual Do Utinga(PEUt), Belém-Pa.

CARDOSO, T.M; MONTEIRO, F.F; VENTURIERIE. A,CAMPOS, G.S. Analise Multitemporal da Área de Protenção Ambiental de Belém. 


\begin{tabular}{|c|c|}
\hline $\begin{array}{l}\text { XVII Simpósio Brasileiro } \\
\text { de Geografia Fisica Aplicada } \\
\end{array}$ & $\begin{array}{l}\text { OS DESAFIOS DA GEOGRAFIA FÍSICA NA FRONTEIRA DO CONHECIMENTO } \\
\text { Instituto de Geociências - Unicamp }\end{array}$ \\
\hline $\begin{array}{l}\text { I Congresso Nacional } \\
\text { de Geografia Física }\end{array}$ & $\begin{array}{l}\text { Campinas - SP } \\
28 \text { de Junho à } 02 \text { de Julho de } 2017\end{array}$ \\
\hline
\end{tabular}

CARLOS, Ana Fani Alessandri. A Cidade. 5. Ed. - São Paulo: Contexto, 2001. - (Repensando a Geografia).

CRÓSTA, A. P, Processamento Digital de Imagens de Sensoriamento Remoto, Campinas, SP, UNICAMP,ed. rev., 1993.

PARÁ. Secretaria de Ciência, Tecnologia e Meio Ambiente. Parque Ambiental de Belém: Plano de Manejo. SOFRELEC: Belém, 1994. 60p.

SEMAS, Parque Estadual Utinga(PEUt) e Área de Protenção Ambiental Da Região Metropolitana De Belém. Disponivel em www.semas.pa.gov.br/diretorias/areas-protegidas/peut/apresentacao. 